\title{
Knowledge Exchange in Intra-Organizational Innovation Communities: The Role of Cognitive and Affective States
}

\author{
Bastian Bansemir, Center for Leading Innovation \& Cooperation (CLIC), HHL - Leipzig Graduate School of Management, Germany, \\ E-Mail: bastian.bansemir@hhl.de \\ Anne-Katrin Neyer, Fraunhofer Center for Middle and East Europe, Leipzig, Germany, E-Mail: anne-katrin.neyer@moez.fraunhofer.de \\ Kathrin M. Möslein, Information Systems I - Innovation \& Value Creation, University of Erlangen-Nuremberg, Germany \& Center for Leading Inno-
} vation \& Cooperation (CLIC), HHL - Leipzig Graduate School of Management, Germany, E-Mail: kathrin.moeslein@wiso.uni-erlangen.de

\begin{abstract}
Many aspects in the area of designing platforms for intra-organizational innovation communities are not well understood. In this article, we examine the impact of technologically induced psychological factors on knowledge exchange in such communities. Using two experimental pretest-posttest experiments, we find that the implementation of (i) technologically induced self-efficacy (expressed by a 'hurray' message) and (ii) technologically induced positive affect (expressed by playing some 30 seconds of rock-' $n$ '-roll music) in the design of the platform results in an influential increase of knowledge exchange. Importantly, the studies suggest that the integration of technologically induced self-efficacy leads to a higher extent of knowledge exchange than technologically induced positive affect. The implications of these results for future research and practice as well as for the design of a platform for such communities are discussed.
\end{abstract}

JEL classification: $M 100$, M12O

Keywords: Innovation community, knowledge processes, cognition and affect

Manuscript received April 21, 2011, accepted by Peter Walgenbach (Management) December 21, 2011.

\section{$1 \quad$ Introduction}

Organizations have devoted substantial resources to initiating and maintaining innovation management systems in order to capture and exploit knowledge of their employees in the pursuit of innovation. However, they still struggle to improve the innovative results of these systems as they mostly produce incrementally rather than radically new propositions (Fairbank and Williams 2001; Van Dijk and van den Ende 2002; Amin and Roberts 2008). To overcome this issue, organizations increasingly engage in knowledge exchange through communityoriented efforts among employees. In line with Grant (1996), Swan, Newell, Scarbrough, and Hislop (1999) and Zarraga and Bonache (2005) knowledge exchange is defined as the sharing, acquisition, combination and usage of knowledge among individuals. This social tendency (i.e., com- munity-oriented efforts) is orchestrated by the development of social software or Web 2.0 applications like wikis, weblogs, instant messaging services, group editors, social tagging services or social networking services, i.e., technical features able to support knowledge exchange and community-oriented efforts on platforms (e.g., Koch, Bullinger, and Möslein 2009). In line with Koch, Bullinger, and Möslein (2009) platforms may be understood as information and communication technologies mostly web-based and including a multitude of Web 2.0 features.

In this vertex of the 'social' and the 'technical', a distinct form of community is emerging: intraorganizational innovation community. By juxtaposing differences and similarities of research done, ranging from communities of practice (Brown and Duguid 1991; Wenger 1998; Amin and Roberts 
2008) to virtual communities (Bieber, Engelbart, Furuta, Hiltz, Noll, Preece, Stohr, Turoff, and van de Walle 2002; Ardichvili, Page, and Wentling 2003), intra-organizational innovation communities are defined by the following characteristics: (i) Existence of a shared purpose to search, select and develop innovations in line with an organization's strategic objectives. (ii) Members are limited to employees of a particular organization, but not to any specific function or department, such as research and development. (iii) Interaction and communication of members primarily takes place on platforms, particularly enabled and supported by social software and Web 2.o. (iv) Neither sustained and ongoing mutual relationships nor mutual interdependence are pre-requisites. However, informal interaction and open communication are a major longterm goal.

While previous research offers a good understanding of how communities of practice or virtual communities achieve their goals, organizations still experiment with how intra-organizational innovation communities can be supported in their endeavors to create innovations in an online context. Thereby, the challenge of how to foster knowledge exchange as a precondition for innovation needs to be tackled. Among other areas, organizations need to identify ways to overcome stickiness of knowledge, cognitive distance and ambiguity (Amin and Roberts 2008; Hippel 1994; Amabile, Barsade, Mueller, and Staw 2005; Isen 2001; Isen, Niedenthal, and Cantor 1992). Previous attempts to attain these issues mostly build on trust- and motivation-related aspects (e.g., Chiu, Hsu, and Wang 2006; Franke and Shah 2003; Ebner, Leimeister, and Krcmar 2009). Still, studies do not take full advantage of existing knowledge from adjacent fields, such as psychology, to gain a nuanced understanding (e.g., Bishop 2007; Chiu, Hsu, and Wang 2006). Based on a conscious screening of theoretical perspectives, dealing with psychological functioning of individuals, we identify two promising means to tackle this issue. Building on social cognition theory (Bandura 1986; Wood and Bandura 1989) and behavioral motivation theory (Gray 1981; Gray 1990; Watson, Wiese, Vaidya, and Tellegen 1999; Ilies and Judge 2005), we argue that stickiness of knowledge, cognitive distance and ambiguity in intra-organizational innovation communities may be overcome through two means: First, knowledge exchange is proposed to be fostered if community members are able to cope with ambiguity by technologically induced cognitive stimulation. Following Bandura (1986) and Wood and Bandura (1989), we define cognition as mental processes of information transformation and restructuring in the pursuit of problem solving. Second, community members are proposed to be more likely to engage in knowledge exchange if stickiness of knowledge and cognitive distance are reduced by technologically induced affective stimulation, resulting in availability of mental material and cognitive flexibility. In line with Amabile, Barsade, Mueller, and Staw (2005) and Isen, Niedenthal, and Cantor (1992) affective states may best be described as having good (positive affect) or bad feelings (negative affect).

Thus, using two experimental pretest-posttest experiments, the purpose of the paper is to explore and test if psychological factors (i.e., cognitive and affective states) can be technologically induced in intra-organizational innovation communities and if so, do they have the potential to stimulate knowledge exchange in the intended way?

\section{Theoretical Background and Hypotheses}

\subsection{Technologically induced self-efficacy and knowledge exchange}

Previous research in psychology and innovation management analyzes the relation among cognitive factors, external environments and individual performance such as the extent of knowledge exchange (Bandura 1986; Quigley, Tesluk, Locke, and Bartol 2007; Wood and Bandura 1989). Several researchers hinted at the possibility that cognitive stimulation may deliver the needed impetus for community members to overcome barriers related to knowledge exchange (Dahlander, Frederiksen, and Rullani 2008; Franke and Shah 2003; Hsu, Ju, Yen, and Chang 2007; Krogh, Spaeth, and Lakhani 2003; Lin 2007; Quigley, Tesluk, Locke, and Bartol 2007). Also, scholars in information systems and innovation management have studied if and if so how technical features may influence cognitive factors, such as motivation or trust (Ebner, Leimeister, and Krcmar 2009; Shah 2006; Leimeister, Ebner, and Krcmar 2005). They showed that technical features have the potential to exert considerable influence on cognitions. Given these potentials we argue that the implementation of technologically induced selfefficacy in the design of a platform for intraorganizational innovation community is likely to 
foster the following three effects of self-efficacy: 1 ) perseverance under conditions of difficulties 2) perseverance under conditions of threats and 3) ambition towards challenging tasks (Bandura 1986; Wood and Bandura 1989).

First, self-efficacy has a positive influence on perseverance and extent of effort in situations of difficulties, as individuals do not doubt their abilities (Wood and Bandura 1989). Accordingly, the manner in which individuals cope with situations characterized by difficulties can be influenced by whether individuals exhibit more or less self-efficacy. Difficulties with regard to knowledge exchange often result from stickiness of knowledge (i.e., knowledge that is hard to transfer; Amin and Roberts 2008; Hippel 1994). For example, transfer of implicit knowledge remains difficult, as individuals find it demanding to codify implicit knowledge into clear descriptions or rules. Given the characteristics of intra-organizational innovation communities we propose that if difficulties in knowledge exchange occur, those individuals who experience technologically induced self-efficacy will exert greater effort to overcome these difficulties and will not quickly give up.

Second, Wood and Bandura (1989) found in their studies on complex organizational decision making that threatening situations create high levels of stress and feelings of loss of control. Threatening situations may stem from multiple sources such as a recession at the macro level or mobbing at the micro level to name only two (e.g., Peacock and Wong 1990; Leymann 1996). According to Wood and Bandura (1989), self-efficacy reduces these feelings in threatening situations as individuals remain focused on finding solutions and do not get overwhelmed by anxious feelings. In consequence, stress and perceived loss of control do not constrain activities of individuals with self-efficacy in situations of threat. Studies showed that knowledge exchange for innovation purposes within communities is a complex and ambiguous process, in which results are rarely predictable (Østerlund and Carlile 2005; Sawhney and Prandelli 2000). Having said this, we propose that in intra-organizational innovation communities, those community members who experience technologically induced self-efficacy are less likely to exert stress and feelings of losing control, and thus will engage more in knowledge exchange.

Third, self-efficacy stimulates individuals' ambitions to take action on challenging tasks. Self-efficacy enables individuals to conceive difficult and challenging objectives and tasks as realistic options for action (Wood and Bandura 1989). Consequently, individuals experiencing self-efficacy are likely not to focus on possible negative results of their engagement but to embrace challenging tasks with excitement. Still, exchanging knowledge in the pursuit of intra-organizational innovation communities may be challenging for employees who are not specifically educated or trained in this domain. Also, the fact that they are required to exchange knowledge with cognitive-distant colleagues - e.g., employees from different professional backgrounds - might increase their perception of working on a (too) challenging task. We argue that community members who experience technologically induced self-efficacy will be likely to meet these challenges, as they feel capable to handle them. Consequently, they will positively engage in knowledge transfer within intra-organizational innovation communities.

Although these three effects unfold and influence individuals' cognitions separately mainly by reducing psychological barriers, they all propose that the implementation of technologically induced selfefficacy in the design of a platform will lead to an increase of knowledge exchange in intraorganizational innovation communities. Therefore, our first hypothesis reads as follows:

Hypothesis 1: The more technologically induced self-efficacy individuals experience, the more likely they will be to engage in knowledge exchange in intra-organizational innovation communities.

\subsection{Technologically induced positive affective and knowledge exchange}

Researchers in psychology and creativity have studied the relation between affective states and activities, such as knowledge exchange, in great depth (Amabile, Barsade, Mueller, and Staw 2005; Isen, Niedenthal, and Cantor 1992; Martin, Ward, Achee, and Wyer 1993; Watson, Wiese, Vaidya, and Tellegen 1999; Wood and Bandura 1989). They argued that positive affect induction facilitates innovationrelated knowledge exchange as it leads to cognitive variation that stimulates creativity (Amabile, Barsade, Mueller, and Staw 2005; Isen 2001; Isen, Niedenthal, and Cantor 1992). For instance, Fredrickson (1998: 304) stated that “[...] experienc- 
es of certain positive emotions prompt individuals to discard time-tested or automatic (everyday) behavioral scripts and to pursue novel, creative, and often unscripted paths of thought and action".

Moreover, Isen, Niedenthal, and Cantor (1992) as well as Amabile, Barsade, Mueller, and Staw (2005) demonstrated that positive affect can be technologically induced. Thus, we argue that the implementation of technologically induced affect in the design of the platform of an intra-organizational innovation community will strengthen the following three effects of positive affect of community members: 1 ) availability of mental material, 2) cognitive flexibility and 3) processable complexity (e.g., Amabile, Barsade, Mueller, and Staw 2005; Isen, Niedenthal, and Cantor 1992).

First, availability of mental material (i.e., availability and access to potentially relevant information) is increased by positive affect. Specifically, several studies indicated that positive affect results in more information being available and accessible as individuals' scope of attention broadens (Amabile, Barsade, Mueller, and Staw 2005; Fredrickson 1998; Isen, Niedenthal, and Cantor 1992; Martin, Ward, Achee, and Wyer 1993). Given the characteristics of intra-organizational innovation communities, we argue that technologically induced positive affect may unleash community members' mental materials to overcome stickiness. In this case, community members are proposed to be more mentally 'awake' to handle issues of sticky knowledge and hence outperform in innovation development. It is important to note that this argument and the following hold true for psychological healthy employees. Employees suffering from psychological illnesses may need a different treatment.

Second, positive affect is found to enhance individuals' cognitive flexibility, as more and different associations, for instance multiple alternatives to solve a problem, are likely to emerge (Amabile, Barsade, Mueller, and Staw 2005; Isen, Niedenthal, and Cantor 1992). Isen, Niedenthal, and Cantor (1992) showed that individuals under positive affect are open-minded, in the sense that they are unbiased, adaptive in thinking, embrace information etc. Individuals are more likely "[...] to switch perspectives or entertain alternative perspectives to deal with data and solve a problem" (Isen, Niedenthal, and Cantor 1992: 58). Consequently, individuals experiencing positive affect are likely to embrace divergent information and adapt their thinking to increase cognitive flexibility. As in intra-organizational inno- vation communities cognitive-distant individuals are required to interact, we argue that those individuals experiencing technologically induced positive affect switch or entertain multiple perspectives. This supports the emergence of a common understanding, forming the basis for knowledge exchange among cognitive-distant individuals in the community setting.

Third, individuals engaging in knowledge exchange need to be able to handle and make sense of arising complexity, resulting from multiple influences. Research on affect posits that processable complexity is increased as a result of positive affect induction (Amabile, Barsade, Mueller, and Staw 2005). In this case, abilities to process complexity are elevated, as multiple factors are considered at the same time, realistic evaluations of situations are developed and beneficial coping is achieved (Isen 2002). Again, given the multitude of information available in intra-organizational innovation communities, community members are required to deal with the inherent complexity. Thus, we argue that community members experiencing technologically induced positive affect will be able to do so, whereas those who experience no positive affect will be less able to do so.

Hitherto, we propose that knowledge exchange among intra-organizational community members can be enhanced by technologically induced positive affect. Hence, our second hypothesis reads as follows:

Hypothesis 2: The more technologically induced positive affect individuals experience, the more likely they will be to engage in knowledge exchange in intra-organizational innovation communities.

\section{$3 \quad$ Research Methods}

Two experimental pretest-posttest studies were conducted, testing each hypothesis in a university setting. Study 1 relates to hypothesis 1 in that technologically induced self-efficacy was manipulated (i.e., self-efficacy beliefs of participants were increased by platform-provided encouragements or frankly communicated hurray messages). Study 2 tests hypothesis 2, in that technologically induced positive affect was increased (i.e., positive affect was induced to participants by music or, in other words, by rock 'n' roll) and unexpected presents. Both studies were designed equally in the sense that they applied similar procedures, control techniques, 
measures etc. Due to similarities, the design of the two experimental studies, the experimental task and procedures are displayed first, followed by detailed explanations related to conducted manipulations. The following sections are structured in the description of the experimental design, experimental task, procedure, manipulations, measures and manipulation check.

\subsection{Experimental design}

We used a pretest-posttest between-subjects experimental design (study 1: technologically induced self-efficacy vs. no technologically induced selfefficacy and study 2: technologically induced positive affect vs. no technologically induced positive affect, e.g., Campbell and Stanley 1963; Christensen 2007; Sarris 1990). The following figure displays this design, equally representing the design of study 1 and study 2 . It shows that participants were randomly assigned (R) to either experimental or control group (between-subjects design). Moreover, it exhibits that the pretest measure of the dependent variable (Y) (in our case knowledge exchange) was conducted before the treatment (X) was installed, by means of our technologically induced self-efficacy and positive affect stimuli. It also becomes clear that the posttest measure of the dependent variable $(\mathrm{Y})$ was conducted after participants were exposed to the treatment condition. Finally, it is shown that statistical analysis focuses primarily on differences of the dependent variable (i.e., knowledge exchange) between the experimental and control group controlling for possible time effects (pretest-posttest design).

\section{Figure 1: Experimental design}

\begin{tabular}{|c|ccccc|}
\hline & $\begin{array}{c}\text { Pretest } \\
\text { measure }\end{array}$ & Treatment & $\begin{array}{c}\text { Posttest } \\
\text { measure }\end{array}$ & Difference \\
\hline $\begin{array}{c}\text { Experimental } \\
\text { group }\end{array}$ & $\mathrm{Y}$ & $\mathrm{X}$ & $\mathrm{Y}$ & Pre-Y - Post-Y \\
$\begin{array}{c}\text { Control } \\
\text { group }\end{array}$ & $\mathrm{R}$ & $\mathrm{Y}$ & & $\mathrm{Y}$ & Pre-Y - Post-Y \\
Compare
\end{tabular}

Notes: The pretest-posttest between-subjects experimental design, including the randomization strategy $(R)$, pretest and posttest measure of knowledge exchange $(Y)$ and self-efficacy and positive affect manipulations $(X)$.

Both studies were conducted in lectures on business administration and included graduate students, enrolled in a large German university. The first experimental study involved 78 participants with an average age of 24 years (standard deviation $=1.99$ ), of whom 42 were male and 36 female. The second study involved 53 participants with an average age of 24 years (standard deviation $=3.20$ ), of whom 36 were male and 17 female. Participants in both studies were randomly assigned to either experimental or control conditions. A self-reporting questionnaire concerning the dependent variable was conducted at the beginning and at the end of the experiment. As students exchanged knowledge all along the lectures and the experiments were conducted midway through the lectures, the pretest-posttest approach enabled to control for knowledge exchange prior to the experiments. Manipulation checks were conducted at the end. Participation made up $10 \%$ of the overall class grading.

\subsection{Experimental tasks}

In both studies, participants completed an idea generation task, in which $50 \%$ of the participants experienced a stimulus. They were asked to develop strategies concerning the introduction of innovation communities. The specific objective of the task was to develop original, but applicable ideas. The task was kept broad, especially to foster the creation innovative views, ideas and concepts. To develop innovative views, ideas and concepts, participants needed to have some basic impetus to find the task relevant for their studies. Two strategies were followed to ensure participation: First, a relatively small percentage (10 \%) of the overall class grading depended on conducted activities. Second, community-related tasks were integrated in courses' tenors and provided a method to develop ideas for a written assignment, due at the end of the course and making up a considerable percentage (50 \%) of the overall grading.

\subsection{Procedure}

In both studies, an innovation-supporting community platform was provided, developed in the course of actions of a funded research project. To give the reader a feeling of how the provided platform looks, the starting page of the platform is displayed in Appendix A1 exemplary. The platform provided common community functionalities - e.g., individual profiles, interest groups etc. - and innovation support functionalities - e.g., innovation profiles, tech clouds, etc. Additionally, the platform supported collaborative innovation generation, refinement of innovation and peer evaluation.

To fulfill the task, participants were asked to traverse a three-step process (i.e., innovation genera- 
tion, refinement and evaluation). This step-wise development of innovations reflects procedures typically applied in corporate intra-organizational innovation communities, such as Cisco, Daimler, IBM, Intel, Siemens, Vodafone among others (for a compilation of examples, see Zerfaß and Möslein 2009). In the first step, participants generated a considerable number of minor and unstructured ideas, using a virtual whiteboard integrated in the community platform. As starting points, participants merged and refined these ideas developing more sophisticated concepts in the second step. In the third step, participants evaluated the concepts of other participants, applying a collaborative scoring method. Each step was announced during the lecture and participants had the following week, until the next session, to get the task done. Participants were free to choose the time and space for their activities in the community. Additionally, they were encouraged to generate ideas, and refine or comment on others' concepts, as this was partly reflected in the grading.

All participants were randomly and equally assigned to either the experimental or control group in both studies. Experimental and control groups were run simultaneously, however, working on separated but alike community platforms. Participants were told that two separated platforms were used due to technical issues to reduce participants' speculations about why two groups had been implemented. Randomization ensured control of extraneous variables (Campbell and Stanley 1963; Christensen 2007), whereas parallel groups provided control over relevant disturbing factors, as both groups were exposed to similar events (Sarris 1990) - e.g., information given during courses or other events not related with the university. Separation of the community platform for experimental and control groups was necessary to prevent spill-over effects of manipulations and thus, ensured precise attribution of set stimuli.

\subsection{Manipulations}

\subsubsection{Technologically induced self-efficacy}

Wood and Bandura (1989) distinguished between four major sources for individuals to enhance selfefficacy. Self-efficacy arises from 1) persuasion (i.e., realistic encouragements), 2) modeling (i.e., watching others succeeding through persistent effort), 3) mastery experiences (i.e., overcoming difficulties through persistent effort) and 4) fitness (i.e., enhanced physical status). In this study, we manipulated the persuasion aspect by creating encouraging messages concerning the given innovation task. Contrary to implied importance of individuals as effective efficacy builders (Wood and Bandura 1989), we focused on the technologically induced self-efficacy by positioning encouraging messages directly on the community platform with no individual interaction whatsoever. Each time participants of the experimental group logged-in the community platform, the encouraging message was displayed for 15 seconds. The message, derived from existing literature, concerned with inducing selfefficacy beliefs based on persuasion (Bishop 2007; Schwarzer and Jerusalem 1995; Wood and Bandura 1989), was the following: 'You can achieve something exceptional! Start here and today: create something great by starting small, think outside regular patterns of thought and show that you are special! Search and create a gorgeous idea, together with your friends and student colleagues!' In a similar appearance, a message stating 'You are loggedin' was posted on the community platform of the control group.

\subsubsection{Technologically induced positive affect}

Isen, Niedenthal, and Cantor (1992) and Amabile, Barsade, Mueller, and Staw (2005) distinguished three major strategies to induce positive affect. Positive affect develops from 1) events - e.g., surprising with an unexpected treat or gift,- 2 ) film clips e.g., showing a comedy - or 3) music - e.g., playing affect-laden music. We focused on event and music aspects within the experimental group as technologically induced positive affect. Showing film clips was not applied in order to keep manipulations as straightforward and short as possible. First, a virtual animated gift card, thanking participants for their engagement, was provided. Second, each time participants opened the community platform in their browser, energizing music started to play before fading out after around 30 seconds. The message printed on the gift card was derived from existing literature (Isen, Niedenthal, and Cantor 1992). It reads as follows: 'Before you start to innovate on the community platform, there is one more thing: We, the members of the research team, wish to express our appreciation for your participation with this thank-you card. So, this is for you!' Similar to study 1, a message stating 'You are logged-in' was posted 
on the community platform of the control group. For a detailed report of the affect manipulation please refer to Appendix A2.

\subsection{Measures}

One week before launching the community platform and directly after completing the assigned tasks, participants responded to a self-reporting questionnaire, including demographic information and questions concerning knowledge exchange. This approach was in accordance with a pre- and postresponse measure, diminishing test effects, such as history and maturation effects, as they occurred in the experimental and control group alike and, thus, were controlled (Sarris 1990; Stanley and Campbell 1966).

To assess the dependent variable knowledge exchange we applied two independent measures: 1) a self-reporting knowledge-exchange scale and 2) a platform-based indicator of actual knowledgeexchange activities. These variables were gathered and analyzed independently and separately in order to eliminate common-method bias as a competing explanation for differences of variance, possibly resulting from self-reporting constructs (Avolio, Yammarino, and Bass 1991; Cote and Buckley 1987; Donaldson and Grant-Vallone 2002; Podsakoff, MacKenzie, Lee, and Podsakoff 2003).

First, we assessed knowledge exchange based on Zárraga and Bonache's (2005) five item selfreporting construct, measured on a seven-point Likert scale (ranging from $1=$ strongly disagree to 7 $=$ strongly agree). The scale has been adapted to community context - e.g., the terms 'work team' were replaced by 'community'. One sample item is: 'In the community, I have shared knowledge and experiences from my past (education or practice experience) that only I knew' (Zárraga and Bonache 2005: 676). Items for all applied constructs are provided in appendix A3. Similar to the findings of Zárraga and Bonache (alpha = 0.74) (2005: 669), we find acceptable reliability $(a l p h a=0.72)$.

Second, we developed a platform-based knowledgeexchange indicator. The indicator automatically calculated points based on individuals' actual activities on the community platform. Participants gained points from three major activities, concerning knowledge exchange: exchanging opinions, sharing ideas and commenting on concepts. All activities were equally weighted to keep the platform-based indicator straightforward. To ensure that knowledge was actually exchanged only those activities, which were rated useful by other participants and had a minimum number of two hundred characters, increased the number of points. This additional measure served two specific objectives: First, due to differences in construction between the selfreported and the platform-based constructs, common-method bias was restricted in terms of applying dissimilar types of constructs (Avolio, Yammarino, and Bass 1991; Donaldson and GrantVallone 2002). Second, as data were collected via self-reported scales and actual activities on the community platform, common-method bias was further limited in the sense that data were collected from different sources (i.e., self-reported vs. actual activities; Cote and Buckley 1987).

\subsection{Manipulation checks}

After completing assigned tasks and answering the post-response measure, we conducted the manipulation check at the beginning of the following lecture in order to minimize risks of priming and reduce response bias. The main page of the community platform and the screen after logging-in were shown. The box, which contained the message during the experiment, was shown in plain color without any text. Participants were asked to remember the log-in situation and to answer a short questionnaire, which contained manipulation checks.

Study 1: To assess technologically induced selfefficacy, Schwarzer and Jerusalem's (1995) ten-item construct on self-efficacy, measured on a six-point scale (ranging from $1=$ not at all true to $6=$ exactly true) was applied. One sample item reads as follows: 'I can always solve difficult problems if I try hard enough'.

Study 2: To check manipulation of technologically induced positive affect we measured positive affect by applying Amabile, Barsade, Mueller, and Staw's (2005: 379) self-rated mood measure, consisting of six items. The first five items relate to specific feelings, rated on a seven-point Likert scale (ranging from $1=$ strongly disagree to $7=$ strongly agree) . One sample item reads as follows: 'While working on the platform, I felt ... ... happy'. The sixth item related to feelings of working with the community platform. It was measured on a seven-point Likert scale, ranging from 'extremely negative' to 'extremely positive'. 


\section{$4 \quad$ Results}

Before conducting actual statistical procedures concerning manipulation checks or comparisons of experimental and control groups, we investigated if the constructs achieved previously reported quality levels to ensure good item and scale quality in the present studies. Several tests were administered, due to space constraints and overall satisfying results, only values for Cronbach's $\alpha$ are reported. The following two sections present the findings of the studies: First, results from self-efficacy manipulation are displayed, followed by findings from positive affect manipulation.

\subsection{Manipulation checks}

\subsubsection{Study 1}

We find reliability coefficients achieving acceptable values - e.g., Cronbach's $\alpha=0.74$ ). An ANOVA conducted on the manipulation check measures reveals significantly higher values of technologically induced self-efficacy among participants of the experimental group, compared to the control group ( $\mathrm{F}$ [72] $=11.78, \mathrm{p}<0.01$, adjusted $\mathrm{R}^{2}=0.23$ ). In line with our manipulation, the analysis reveals lower mean values for self-efficacy for the control group ( mean value $=2.81$, standard deviation $=0.76$ ) compared to the experimental group (mean value $=$ 3.51 , standard deviation $=0.73$ ). These results support that our manipulation of technologically induced self-efficacy (i.e., using platform-provided messages) was successful.

\subsubsection{Study 2}

Reliability coefficients of the positive affect construct, produce acceptable values (Cronbach's $\alpha=$ o.80). An ANOVA conducted on the manipulation check exhibits significantly higher values of technologically induced positive affect among participants of the experimental group, compared to the control group $\left(\mathrm{F}[56]=3.79, \mathrm{p}<0.1\right.$, adjusted $\left.\mathrm{R}^{2}=0.05\right)$. Furthermore, descriptive statistics show increased mean values of the experimental group (mean value $=4.18$, standard deviation $=0.75)$ compared to the control group (mean value $=3.65$, standard deviation $=1.22$ ). To conclude, results suggest that technologically induced positive affect (i.e., playing music and giving virtual presents) was successful, and thus, we felt affirmed in our belief that the manipulations had the intended effects.

\subsection{Test of hypotheses}

\subsubsection{Study 1}

According to hypothesis 1, a positive relationship between technologically induced self-efficacy and knowledge exchange is expected. Altogether, statistics deliver satisfying levels for significance and standard deviations. The pretest-posttest comparison reveals a highly significant main effect ( $F$ [156] $=9.530, \mathrm{p}<0.01$, adjusted $\left.\mathrm{R}^{2}=0.11\right)$, such that the experimental group with technologically induced self-efficacy increased knowledge exchange by 0.80 points (pure effect, controlled for learning effects and influences of the community platform). Besides the fact that knowledge exchange increased in both groups, the experimental group achieved considerably higher values (control group: mean value $=4.36$, standard deviation $=0.91$, experimental group: mean value $=4.86$, standard deviation $=0.76$ ) Differences in mean values of the pretest measure of self-reported knowledge exchange (mean of control group $=4.30$ with a standard deviation $=0.64$, mean of experimental group $=4.00$ with a standard deviation $=0.87)$ are not significant $(F[78]=1.61, \mathrm{p}$ $>$ o.1). The self-reported level of knowledge exchange of the pretest measure results from knowledge being exchanged prior to the experiment within the lecture. Reliability coefficients of the knowledge-exchange construct produce acceptable values (Cronbach's $\alpha=0.71$ ). Figure 1 displays the increase of knowledge exchange for both, the control and the experimental group on the selfreporting scale.

Figure 2: Influence of technologically induced self-efficacy on knowledge exchange between control and experimental group based on self-reported knowledge exchange

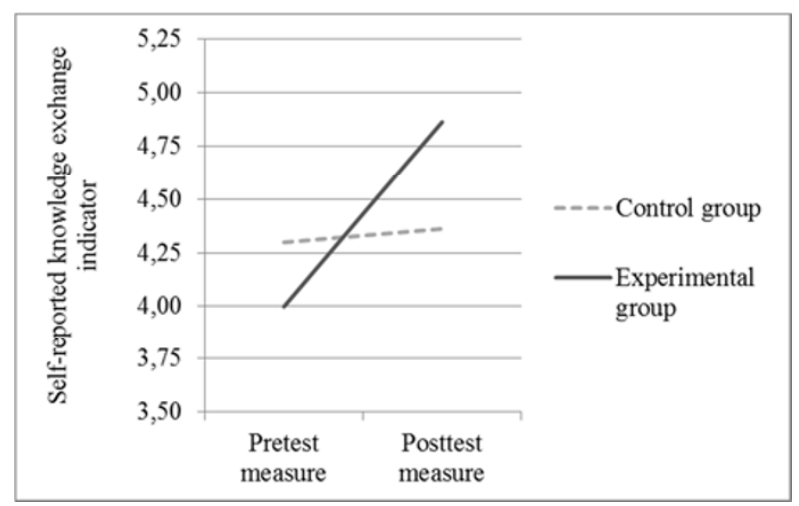


In further support of hypothesis 1, results from the platform-based knowledge-exchange indicator reveal that the experimental group conducted significantly more knowledge-exchange activities compared to the control group $(\mathrm{F}[69]=12.223, \mathrm{p}<$ 0.01 , adjusted $\mathrm{R}^{2}=0.14$ ). Participants in the experimental group conducted nearly twice as many activities related to knowledge exchange as the control group did (experimental group: mean value $=16.20$, standard deviation $=10.79$, control group: mean value $=8.79$, standard deviation $=6.10$ ). Figure 3 shows differences for the control and the experimental group on the platform-based indicator for knowledge exchange.

Figure 3: Influence of technologically induced self-efficacy on knowledge exchange between control and experimental group based on platform-based indicator of knowledge exchange

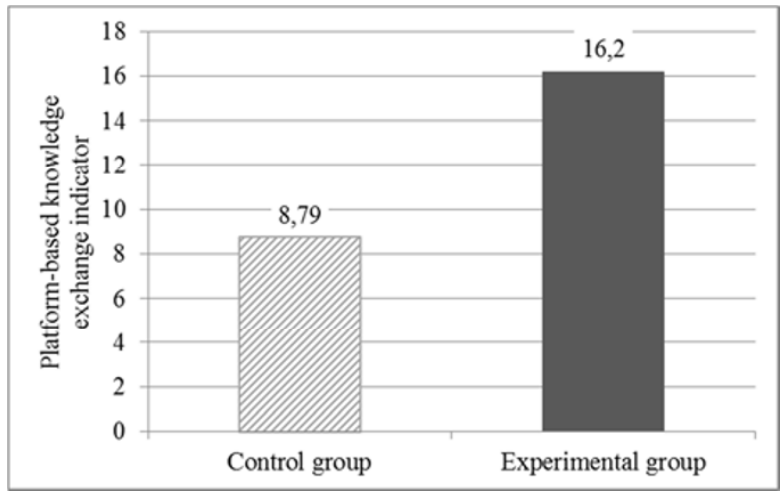

Table 1: Summary of results of study 1

\begin{tabular}{|lllcc} 
Time & $\begin{array}{l}\text { Knowledge- } \\
\text { exchange } \\
\text { measure }\end{array}$ & Group & $\begin{array}{c}\text { Mean } \\
\text { value }\end{array}$ & $\begin{array}{c}\text { Standard } \\
\text { deviation }\end{array}$ \\
\hline Pretest & Self-reported & Control & $\mathbf{4 . 3 0}$ & 0.64 \\
\cline { 2 - 5 } & Experimental & $\mathbf{4 . 0 0}$ & 0.87 \\
\cline { 2 - 5 } & $\begin{array}{l}\text { Platform- } \\
\text { based }\end{array}$ & Control & n.a. & n.a. \\
\cline { 2 - 5 } Posttest & Self-reported & Control & $\mathbf{4 . 3 6}$ & 0.91 \\
\cline { 3 - 5 } & Experimental & $\mathbf{4 . 8 6}$ & 0.76 \\
\cline { 2 - 5 } & Platform- & Control & $\mathbf{8 . 7 9}$ & 6.10 \\
\cline { 3 - 5 } & based & Experimental & $\mathbf{1 6 . 2 0}$ & 10.79 \\
\hline
\end{tabular}

In line with the proposed theoretical arguments, results of the self-reported construct and the activities-based indicator support hypothesis 1. Our findings show that technologically induced self-efficacy via messages posted on the community platform increased knowledge exchange of participants by pushing ambition towards challenging tasks. Table 1 summarizes the results of the data analysis.

\subsubsection{Study 2}

According to hypothesis 2, a positive relationship between technologically induced positive affect and knowledge exchange is expected. The pretestposttest comparison reveals a highly significant main effect $\left(\mathrm{F}[106]=4.40, \mathrm{p}<0.05\right.$, adjusted $\mathrm{R}^{2}=$ 0.07), such that the experimental group with the technologically induced positive affect increased knowledge exchange by 0.84 points (pure effect, controlled for learning effects and influences of the community platform). While knowledge exchange increased in the experimental group considerably, it slightly reduced among participants of the control group (Posttest measure: control group mean value $=4.23$, standard deviation $=1.02$, experimental group mean value $=4.35$, standard deviation $=1.26$, compared to pretest measure: mean of control group $=4.24$, standard deviation $=0.76$, mean of experimental group $=3.52$, standard deviation $=$ 1.06). Reliability coefficients of the knowledgeexchange construct produce acceptable values (Cronbach's $\alpha=0.71$ ). Differences in mean values of the pretest measure of self-reported knowledge exchange are significant $(\mathrm{F}[53]=8.74, \mathrm{p}<0.01$, adjusted $\mathrm{R}^{2}=0.12$ ), even though participants were randomly assigned to the groups. To exclude systematic bias due to differences in demographics, in terms of gender, age or experience distribution between the experimental and control group we ran additional statistical tests. The results confirm that randomization was successful in terms of these variables and thus differences in pretest ratings of knowledge exchange are not related to systematic bias of population. We found no evidence that differences in pretest measures of knowledge exchange would negatively affect the explanatory power of the study. Figure 4 illustrates the above-presented findings.

Additionally, results derived from the platformbased indicator support hypothesis 2 . They reveal a significant increase of knowledge-exchange activities between the control and experimental group ( $\mathrm{F}$ $[69]=4.41, \mathrm{p}<0.05$, adjusted $\left.\mathrm{R}^{2}=0.05\right)$. Participants increased knowledge-exchange activities under treatment condition by more than $50 \%$ (control group: mean value $=4.47$, standard deviation $=3.74$ compared to experimental group: mean value $=$ 
6.89 , standard deviation $=5 \cdot 60)$. Figure 5 summarizes these findings.

Figure 4: Influence of technologically induced positive affect on knowledge exchange between control and experimental group on self-reported knowledge exchange

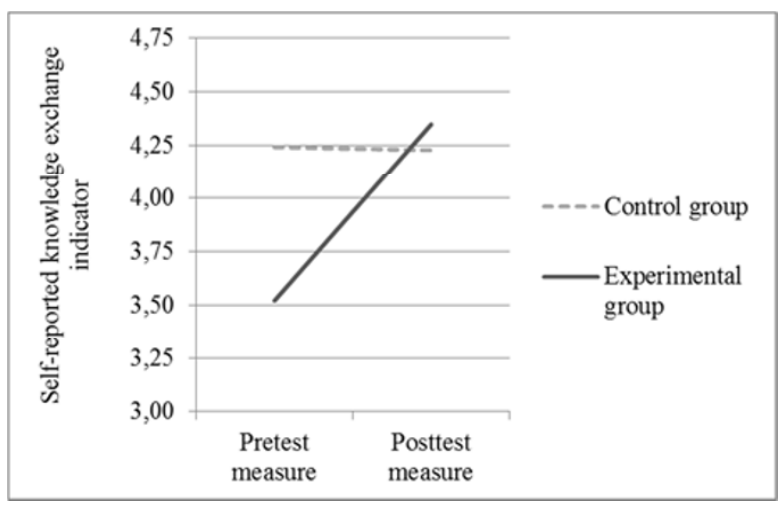

Figure 5: Influence of technologically induced positive affect on knowledge exchange between control and experimental group on platform-based indicator of knowledge exchange

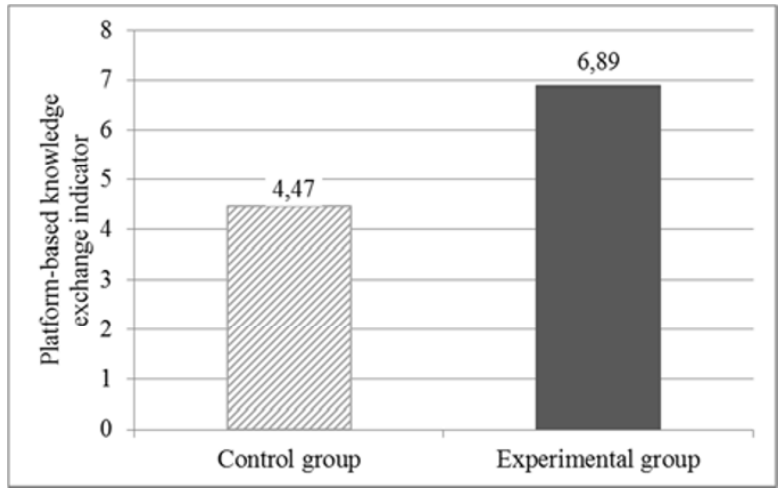

Table 2: Summary of results of study 2

\begin{tabular}{|lllcc} 
Time & $\begin{array}{l}\text { Knowledge- } \\
\text { exchange } \\
\text { measure }\end{array}$ & Group & $\begin{array}{l}\text { Mean } \\
\text { value }\end{array}$ & $\begin{array}{c}\text { Standard } \\
\text { deviation }\end{array}$ \\
\hline Pretest & Self-reported & Control & $\mathbf{4 . 2 4}$ & 0.76 \\
\cline { 2 - 5 } & Experimental & $\mathbf{3 . 5 2}$ & 1.06 \\
\cline { 2 - 5 } & $\begin{array}{l}\text { Platform- } \\
\text { based }\end{array}$ & Control & n.a. & n.a. \\
\cline { 2 - 5 } Posttest & Experimental & n.a. & n.a. \\
\cline { 2 - 5 } & Self-reported & Control & $\mathbf{4 . 2 3}$ & 1.02 \\
\cline { 2 - 5 } & Experimental & $\mathbf{4 \cdot 3 5}$ & 1.26 \\
\cline { 2 - 5 } & $\begin{array}{l}\text { Platform- } \\
\text { based }\end{array}$ & Control & $\mathbf{4 . 4 7}$ & 3.74 \\
\cline { 2 - 5 } & Experimental & $\mathbf{6 . 8 9}$ & 5.60 \\
\hline
\end{tabular}

In sum, results of the self-reported construct and the activities-based indicator support hypothesis 2 . Our findings indicate that technologically induced positive affect via played music and virtual presents posted on the community platform increased knowledge exchange among community members. In Table 2 key data are summarized.

\section{Discussion}

Our studies analyze how technologically induced psychological factors (i.e., cognitive and affective states) implemented in the design of the platform influence knowledge exchange in intraorganizational innovation communities. In general, our findings reinforce the importance of research into technologically induced individual factors impacting knowledge exchange in such communities. In particular, our findings suggest that even though technologically induced selfefficacy and positive affect result in significantly increased knowledge exchange among intraorganizational innovation community members, there is an important difference in how these two types of technologically induced psychological factors are reflected in our data. Whereas community members were more likely to engage in knowledge exchange under conditions of technologically induced self-efficacy, the propensity of community members who engage in knowledge exchange under conditions of technologically induced positive affect was notably lower. Differences between implementing technologically induced self-efficacy and technologically induced positive affect in the design of the platform and its influence on knowledge exchange expressed in levels of significance (ps. of 0.01 and 0.05 respectively), extent of knowledge exchange (increase of behavior indicator of $100 \%$ compared to $50 \%$ ) and predictive power (adjusted $\mathrm{R}^{2} \mathrm{~S}$ of $>$ 0.12 compared to < 0.7) support this notion.

We cannot explain precisely why technologically induced self-efficacy increased knowledge exchange notably more than the technologically induced positive affect stimulation, but can derive the following reasonable explanation: It is possible that existing cognitive barriers reduce the effectiveness of positive affect stimuli. As we did not remove cognitive barriers through technologically induced selfefficacy before implementing technologically induced positive affect in the platform design in study 2 , individuals might not believe in their own skills to 
master difficulties or threatening situations and to tackle challenging tasks. In this case, technologically induced positive affect might not unfold its full potential, as central cognitive barriers have not yet been removed. Thus, the intended outcome of technologically induced positive affect aiming at activation of additional cognitive resources, might be restricted. We conclude that technologically induced positive affect only unfolds effectively if community members feel capable of tackling a task.

This has important implications for organizations, which are ready to implement an intraorganizational innovation community (and might not know in detail how to best design a platform to foster knowledge exchange among community members). Also, it is of high relevance for those organizations which have already implemented an intra-organizational innovation community (and might realize that community members do not exchange knowledge in the intended way).

In particular, it is recommended to first let community members experience technologically induced self-efficacy, for instance in the form of positioning encouraging messages on the start page of the platform. Then, in a next step, they should experience technologically induced positive affect, for instance via affect-laden music. Nevertheless, one has to be aware of not doing 'too much of a good thing'. Even though previous research underlined that playing music induces positive feelings (e.g., Isen, Niedenthal, and Cantor 1992), it is important not to annoy community members by playing music, and thus reduce their willingness to exchange knowledge in the intra-organizational innovation community. Thus, even though it seems at first glance quite easy to integrate relatively minor changes in the design of the platform for the community (e.g., playing some 30 seconds of music), which will then result in an influential impact on knowledge exchange, our findings make a claim for a conscious decision-making in terms of what technologically induced psychological factors should be integrated, and when.

In particular, the question of what would be the appropriate amount of integrating technologically induced psychological factors in the design of a platform for intra-organizational innovation communities cannot be answered in a global way. There may be a benefit to examining the extent to which technologically induced psychological factors affect different types of employees depending on their previous experiences concerning knowledge exchange in the context of innovation development within intra-organizational innovation communities. One possibility could be that core inside innovators (i.e., innovators that are traditionally held responsible for innovation within R\&Ddepartments; Neyer, Bullinger, and Möslein 2009) already possess high levels of self-efficacy with regard to their innovation capacity and, thus, will not respond with increased levels of knowledge exchange due to technologically induced self-efficacy. In contrast, peripheral inside innovators (i.e., innovators across all business units not responsible for innovative activity by their job description; Neyer, Bullinger, and Möslein 2009) might need a high level of technologically induced self-efficacy to foster their engagement in knowledge-exchange activities within such communities. Additionally, it is likely that employees who are engaging in intraorganizational innovation communities for the first time may profit from technologically induced selfefficacy to a higher extent, as they cannot rely on previous success. In contrast, those employees who can build on previous expertise may not experience any differences. Further studies could continue to explore these important issues and help to shed light on how technologically induced self-efficacy and positive affect influence distinct types of employees who have different levels of experience concerning innovation development.

In this regard, we are aware that our use of an experiment with graduate students in a university setting may raise concerns about external validity of our findings. However, Campbell and Stanley (1963) emphasized that external validity depends more on capturing all necessary dimensions and not on the setting. Following this reasoning, our studies do not reflect a laboratory experiment, but were designed as experiments that imitate actual work contexts with regard to engaging in intra-organizational innovation communities as precise as possible. As participants had to attend several other lectures, the work on the innovation task within the community platform required the students to decide on priority setting with regard to their tasks, which corresponds to priority setting by employees within organizations. Also, as a technical platform providing common community functionalities was deployed and a step-wise development of innovations reflecting typical procedures for innovation development in intra-organizational innovation communities was applied, our findings seem to generate high levels of external validity. However, despite the fact that key dimensions imitated actual work contexts, it ap- 
pears impossible to prove that all dimensions were captured accurately. Therefore, we encourage scholars to conduct follow-up studies, testing technologically induced psychological factors such as selfefficacy and positive affect within a corporate context.

We began this paper by suggesting that we are observing a need to gain deeper insights into the design of platforms for intra-organizational innovation communities. Our findings indicate that organizations which are eager to purposively foster innovation should be more cognizant of possibilities and manners to implement technologically induced psychological factors while initially designing or redesigning a platform for intra-organizational innovation communities. This is a major challenge for both, practice and theory. Our studies contribute to this important endeavor, colloquially speaking by identifying hurray messages (i.e., technologically induced self-efficacy) and rock 'n' roll (i.e., technologically induced positive affect) as two such possibilities.

\section{Acknowledgement}

We thank all inside and outside innovators who are part of our ongoing innovation research journey. This research has been funded by project grants from the Federal Ministry of Education and Research (BMBF) and the European Social Fund (ESF) within the project 'Open-I: Open Innovation within the Firm' (FKZ: 01FM07053 \& 01FMo7054) and 'TANDEM: Knowledge exchange in age-diverse settings' (FKZ: 01HH11091). We gratefully acknowledge support by the Peter Pribilla Foundation (project: Leading innovation in a boundaryless world). An earlier version of this paper has been presented at the Academy of Management 2011 (San Antonio, Texas).

\section{Appendix}

\section{A1 Platform design}

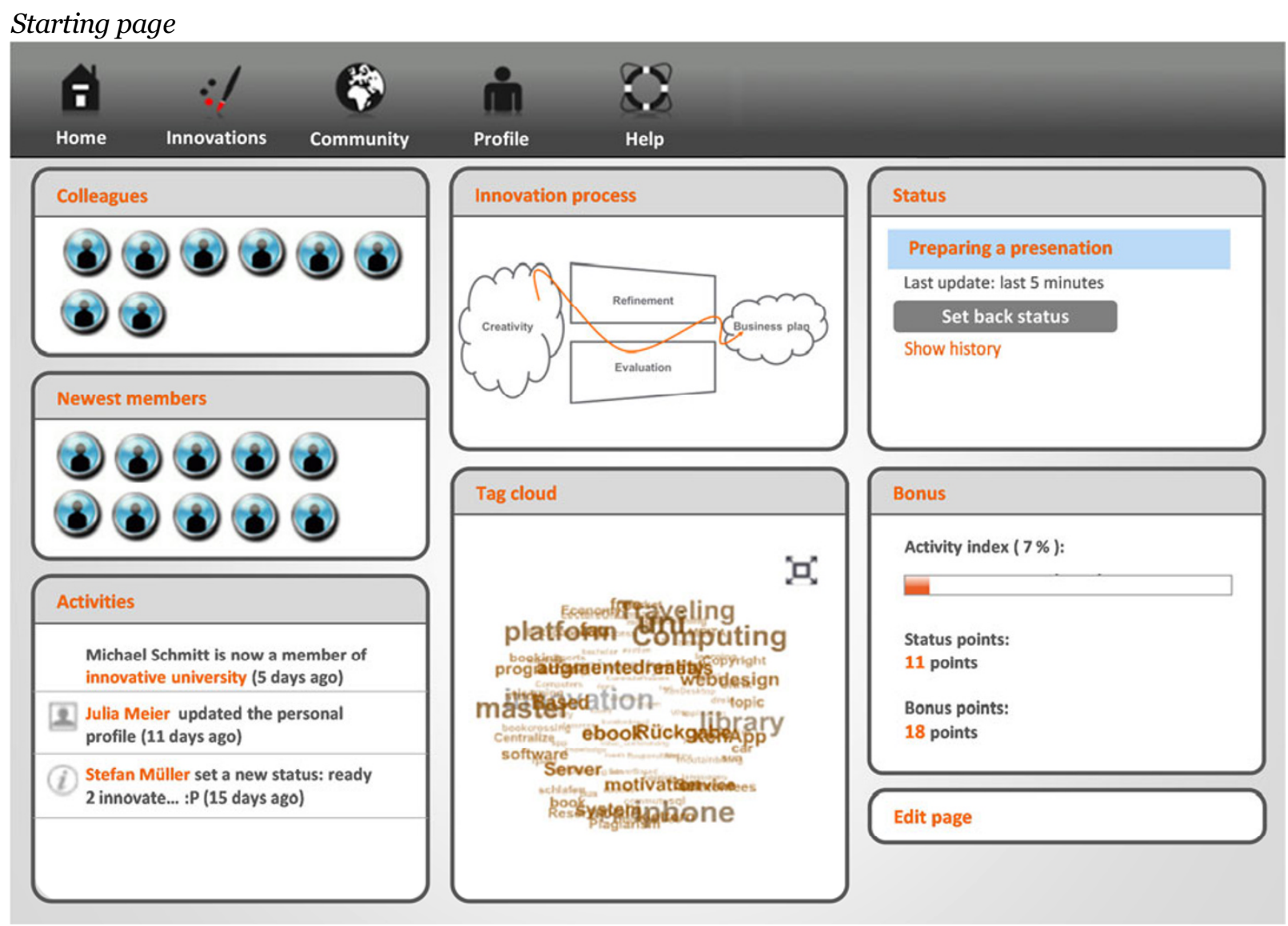



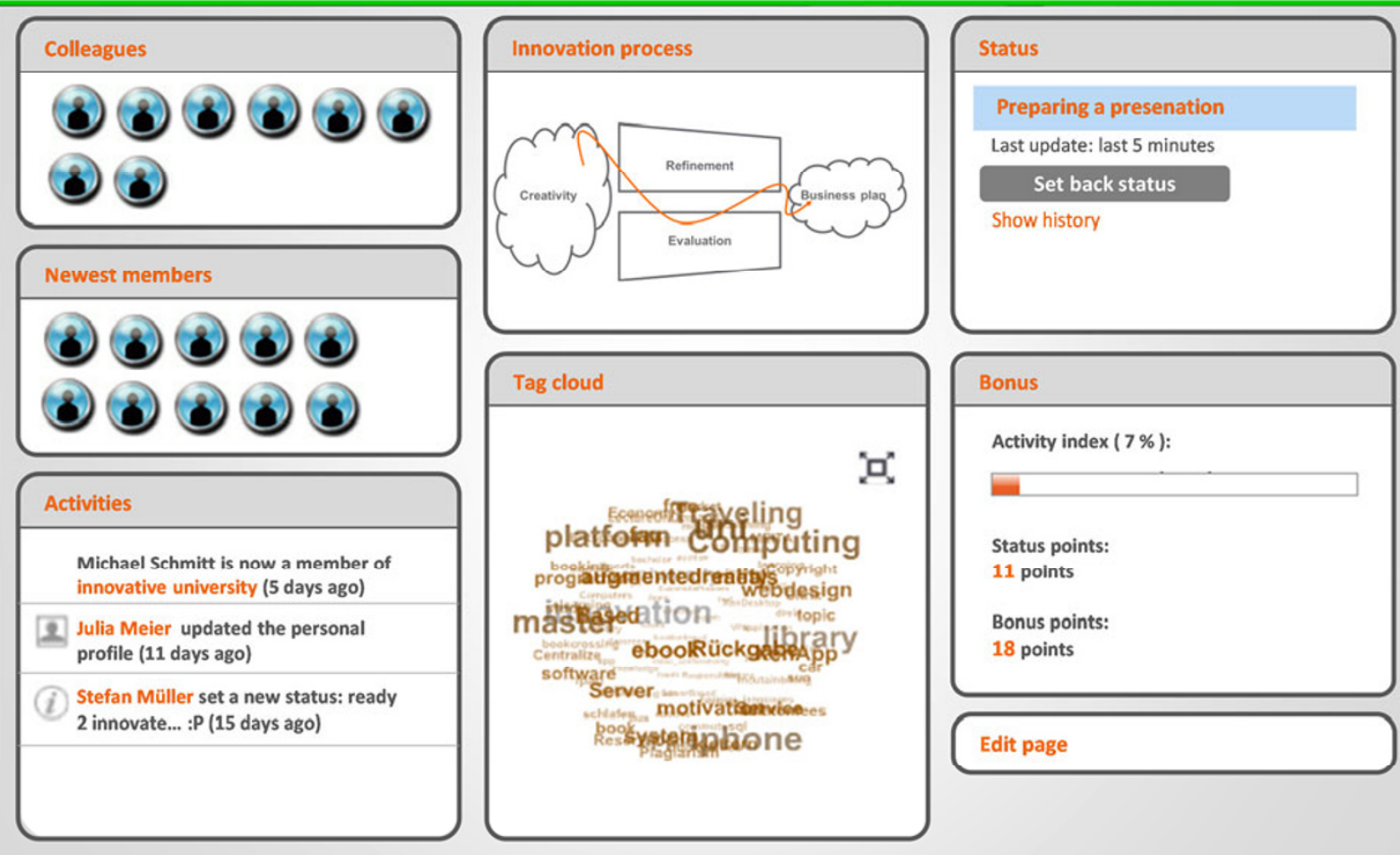

Edit page

\section{A2 Manipulations}

To enable community members to experience technologically induced positive affect, a virtual animated gift card was provided to the experimental group. The gift card, which was retrieved from www.yahoo.americangreetings.com (name of the card is 'a simple thank you'), is displayed below.

thanks :)

Before you start to innovate on the community platform, there is one more thing: We, the members of the research team, are expressing our appreciation of your participation with this thank you card. So, this is for you!

Moreover affect-laden music started to play as soon as community members opened the platform and was played for 30 seconds before fading out. Two songs were selected: 'Limbo Rock' by Chubby
Checker and 'You Can Call Me Al' by Paul Simon. To avoid possible annoyance of community members the song was changed after the first two weeks of working on the platform.

\section{A3 Items used}

\section{Knowledge exchange}

Knowledge-exchange items adapted from Zárraga and Bonache (2005) and measured on a sevenpoint Likert scale (ranging from $1=$ strongly disagree to $7=$ strongly agree):

1. In the community I have learned new things from my fellow students that only they knew.

2. In the community, I have shared knowledge and experiences from my past (education or practice experience) that only I knew.

3. In the community, it is normal that, as a result of ideas contributed by a member, we have exchanged ideas that we had never considered before, and that we subsequently developed.

4. The community has come up with ideas for improvement that the university has subsequently put into operation. 
5. In the community, we have generated many improvements on the traditional way of doing things.

\section{Self-efficacy}

Self-efficacy items as provided by Schwarzer and Jerusalem (1995) measured on a six-point scale (ranging from $1=$ not at all true to $6=$ exactly true):

1. I can always manage to solve difficult problems if I try hard enough.

2. If someone opposes me, I can find the ways and means to get what I want.

3. I am certain that I can accomplish my goals.

4. I am confident that I could deal efficiently with unexpected events.

5. Thanks to my resourcefulness, I can handle unforeseen situations.

6. I can solve most problems if I invest the necessary effort.

7. I can remain calm when facing difficulties because I can rely on my coping abilities.

8. When I am confronted with a problem, I can find several solutions.

9. If I am in trouble, I can think of a good solution.

10. I can handle whatever comes my way.

\section{Affect items}

Affect items taken from Amabile, Barsade, Mueller, and Staw (2005) measured on a seven-point Likert scale (ranging from $1=$ strongly disagree to $7=$ strongly agree):

While working on the platform, I felt ...

1.... happy.

2. ... satisfied with the group.

3. ... enjoyment of work.

4. ... frustrated. (reverse-coded)

5. ... frustrated with the group. (reverse-coded)

The sixth item reads as follows:

6. My feelings about working on the platform were

... (scale ranging from 'extremely negative to extremely positive).

\section{References}

Amabile, Teresa M., Sigal G. Barsade, Jennifer S. Mueller, and Barry M. Staw (2005): Affect and Creativity at Work, Administrative Science Quarterly, 50 (3): 367-403.

Amin, Ash and Joanne Roberts (2008): Knowing in Action: Beyond Communities of Practice, Research Policy, 37 (2): 353369.

Ardichvili, Alexander, Vaughn Page, and Tim Wentling (2003): Motivation and Barriers to Participation in Virtual KnowledgeSharing Communities of Practice, Journal of Knowledge Management, 7 (1): 64-77.
Argote, Linda, Paul Ingram, John M. Levine, and Richard L. Moreland (2000): Knowledge Transfer in Organizations: Learning From the Experience of Others, Organizational Behavior and Human Decision Processes, 82 (1): 1-8.

Avolio, Bruce J., Francis J. Yammarino, and Bernard M. Bass (1991): Identifying Common Methods Variance With Data Collected From a Single Source: An Unresolved Sticky Issue, Journal of Management, 17 (3): 571-587.

Bandura, Albert (1986): Social Foundations of Thought and Action: A Social Cognitive Theory, $1^{\text {st }}$ ed., Prentice-Hall: Englewood Cliffs, NJ.

Bansemir, Bastian and Anne-Katrin Neyer (2009): From Idea Management Systems to Interactive Innovation Management Systems: Designing for Interaction and Knowledge Exchange, in: Hans Robert Hansen, Dimitris Karagiannis, and Hans-Georg Fill (eds.): Business Services: Konzepte, Technologien, Anwendungen, Österreichische Computer-Gesellschaft: Wien, 861-870.

Bieber, Michael, Douglas Engelbart, Richard Furuta, Starr R. Hiltz, John Noll, Jennifer Preece, Edward A. Stohr, Murray Turoff, and Bartel van de Walle (2002): Toward Virtual Community Knowledge Evolution, Journal of Management Information Systems, 18 (4): 11-35.

Bishop, Jonathan (2007): Increasing Participation in Online Communities: A Framework for Human-Computer Interaction, Computers in Human Behavior, 23 (4): 1881-1893.

Breu, Karin and Christopher Hemingway (2002): Collaborative Processes and Knowledge Creation in Communities-of-Practice, Creativity and Innovation Management, 11 (3): 147-153.

Brown, John S. and Paul Duguid (1991): Organizational Learning and Communities-of-Practice: Toward a Unified View of Working, Learning, and Innovation, Organization Science, 2 (1): 40-57.

Brown, John S. and Paul Duguid (2001): Knowledge and Organization: A Social-Practice Perspective, Organization Science, 12 (2): $198-213$.

Campbell, Donald T. and Julian C. Stanley (1963): Experimental and Quasi-Experimental Designs for Research, $1^{\text {st }}$ ed., Rand McNally: Chicago, IL.

Christensen, Larry B. (2007): Experimental Methodology, $10^{\text {th }}$ ed., Pearson, Allyn, and Bacon: Boston, MA.

Chiu, Chao-Min, Meng-Hsiang Hsu, and Eric T. G.Wang (2006): Understanding Knowledge Sharing in Virtual Communities: An Integration of Social Capital and Social Cognitive Theories, Decision Support Systems, 42 (3): 1872-1888.

Cote, Joseph A. and Ronald M. Buckley (1987): Estimating Trait, Method, and Error Variance: Generalizing Across 70 Construct Validation Studies, Journal of Marketing Research, 24 (3): 315318.

Dahlander, Linus, Lars Frederiksen, and Francesco Rullani (2008): Online Communities and Open Innovation: Governance and Symbolic Value Creation, Industry \& Innovation, 15 (2): 115123 .

Donaldson, Stewart I. and Elisa J. Grant-Vallone (2002): Understanding Self-Report Bias in Organizational Behavior Research, Journal of Business and Psychology, 17 (2): 245-260.

Ebner, Winfried, Jan M. Leimeister, and Helmut Krcmar (2009): Community Engineering for Innovations: The Ideas Competition as a Method to Nurture a Virtual Community for Innovations, $R \& D$ Management, 39 (4): 342-356. 
Fairbank, James F. and Scott D. Williams (2001): Motivating Creativity and Enhancing Innovation Through Employee Suggestion System Technology, Creativity \& Innovation Management, 10 (2): 68-74.

Franke, Nikolaus and Sonali Shah (2003): How Communities Support Innovative Activities: An Exploration of Assistance and Sharing Among End-Users, Research Policy, 32 (1): 157-178.

Fredrickson, Barbara L. (1998): What Good are Positive Emotions?, Review of General Psychology, 2 (3): 300-319.

Grant, Robert M. (1996): Toward a Knowledge-Based Theory of the Firm, Strategic Management Journal, 17 (Winter Special Issue): 109-122.

Gray, Jeffrey A. (1981): A Critique of Eysenck's Theory of Personality, in: Hans Jürgen Eysenck (ed.): A Model for Personality, Springer: Berlin, 246-276.

Gray, Jeffrey A. (1990): Brain Systems That Mediate Both Emotion and Cognition, Cognition \& Emotion, 4 (3): 269-288.

Hippel, Eric von (1994): "Sticky Information" and the Locus of Problem Solving: Implications for Innovation, Management Science, 40 (4): 429-439.

Hsu, Meng-Hsiang, Teresa L. Ju, Chia-Hui Yen, and Chun-Ming Chang (2007): Knowledge Sharing Behavior in Virtual Communities: The Relationship Between Trust, Self-Efficacy, and Outcome Expectations, International Journal of Human-Computer Studies, 65 (2): 153-169.

Hussler, Caroline and Patrick Rondé (2007): The Impact of Cognitive Communities on the Diffusion of Academic Knowledge: Evidence From the Networks of Inventors of a French University, Research Policy, 36 (2): 288-302.

Ilies, Remus and Timothy A. Judge (2005): Goal Regulation Across Time: The Effects of Feedback and Affect, Journal of Applied Psychology, 90 (3): 453-467.

Isen, Alice M. (2001): An Influence of Positive Affect on Decision Making in Complex Situations: Theoretical Issues With Practical Implications, Journal of Consumer Psychology, 11 (2): 75-85.

Isen, Alice M. (2002): Missing in Action in the AIM: Positive Affect's Facilitation of Cognitive Flexibility, Innovation, and Problem Solving, Psychological Inquiry, 13 (1): 57-65.

Isen, Alice M., Paula M. Niedenthal, and Nancy Cantor (1992): An Influence of Positive Affect on Social Categorization, Motivation and Emotion, 16 (1): 65-78

Katz, Ralph and Thomas J. Allen (1982): Investigating the Not Invented Here (NIH) Syndrome: A Look at the Performance, Tenure, and Communication Patterns of 50 R \& D Project Groups, $R \& D$ Management, 12 (1): 7-20.

Koch, Michael, Angelika C. Bullinger, and Kathrin M. Möslein (2009): Social Software für Open Innovation, in: Ansgar Zerfaß and Kathrin M. Möslein (eds.): Kommunikation als Erfolgsfaktor im Innovationsmanagement, Gabler: Wiesbaden, 159-175.

Krogh, Georg von, Sebastian Spaeth, and Karim R. Lakhani (2003): Community, Joining, and Specialization in Open Source Software Innovation: A Case Study, Research Policy, 32 (7): 12171241.

Leimeister, Jan Marco, Winfried Ebner, and Helmut Krcmar (2005): Design, Implementation, and Evaluation of TrustSupporting Components in Virtual Communities for Patients, Journal of Management Information Systems, 21 (4): 101-135.
Leymann, Heinz (1996): The Content and Development of Mobbing at Work, European Journal of Work and Organizational Psychology, 5 (2): 165-184.

Lin, Hsiu-Fen (2007): Knowledge Sharing and Firm Innovation Capability: An Empirical Study, International Journal of Manpower, 28 (3/4): 315-332.

Maccurtain, Sarah, Patrick C. Flood, Nagarajan Ramamoorty, Michael West, and Jeremy Dawson (2009): The Top Team, Trust, Reflexivity, Knowledge Sharing and Innovation, Academy of Management Annual Meeting Proceedings, 1-6.

Martin, Leonard L., David W. Ward, John W. Achee, and Robert S. Wyer (1993): Mood as Input: People Have to Interpret the Motivational Implications of Their Moods, Journal of Personality and Social Psychology, 64 (3): 317-326.

Neyer, Anne-Katrin, Angelika C Bullinger, and Kathrin M. Möslein (2009): Integrating Inside and Outside Innovators: A Sociotechnical Systems Perspective, R\&D Management, 39 (4): 410419.

Nonaka, Ikujiro and Hirotaka Takeuchi (1995): The Knowledge Creating Company: How Japanese Companies Create the Dynamics of Innovation, $1^{\text {st }}$ ed., Oxford University Press: New York, NY.

Nooteboom, Bart (2000): Learning by Interaction: Absorptive Capacity, Cognitive Distance and Governance, Journal of Management and Governance, 4 (1): 69-92.

Østerlund, Carsten and Paul Carlile (2005): Relations in Practice: Sorting Through Practice Theories on Knowledge Sharing in Complex Organizations, Information Society, 21 (2): 91-107.

Peacock, Edward J. and Paul T. P. Wong (1990): The Stress Appraisal Measure (SAM): A Multidimensional Approach to Cognitive Appraisal, Stress Medicine, 6 (3): 227-236.

Podsakoff, Philip M., Scott B. MacKenzie, Jeong-Yeon Lee, and Nathan P. Podsakoff (2003): Common Method Biases in Behavioral Research: A Critical Review of the Literature and Recommended Remedies, Journal of Applied Psychology, 88 (5): 879903.

Quigley, Narda R., Paul E. Tesluk, Edwin A. Locke, and Kathryn M. Bartol (2007): A Multilevel Investigation of the Motivational Mechanisms Underlying Knowledge Sharing and Performance, Organization Science, 18 (1): 71-88.

Sarris, Viktor (1990): Methodologische Grundlagen der Experimentalpsychologie, $1^{\text {st }}$ ed., UTB: Stuttgart.

Sawhney, Mohanbir and Emanuela Prandelli (2000): Communities of Creation: Managing Distributed Innovation in Turbulent Markets, California Management Review, 42 (4): 24-54.

Schwarzer, Ralf and Matthias Jerusalem (1995): Generalized SelfEfficacy Scale, in: John Weinman, Stephen C. Wright, and Marie Johnston (eds.): Measures in Health Psychology: A User's Portfolio, $1^{\text {st }}$ ed., Nfer-Nelson: Windsor, UK, 35-37.

Shah, Sonali K. (2006): Motivation,Ggovernance, and the Viability of Hybrid Forms in Open Source Software Development, Management Science, 52 (7): 1000-1014.

Soekijad, Maura, Mirjam A. A. Huis in't Veld , and Bert Enserink (2004): Learning and Knowledge Processes in InterOrganizational Communities of Practice, Knowledge \& Process Management, 11 (1): 3-12. 
Stanley, Julian C. and Donald Thomas Campbell (1966): Experimental and quasi-experimental Designs for research, Rand McNally: Chicago, IL.

Swan, Jacky, Sue Newell, Harry Scarbrough, and Donald Hislop (1999): Knowledge Management and Innovation: Networks and Networking, Journal of Knowledge Management, 3 (4): 262-275.

Van Dijk, Christiaan and Jan van den Ende (2002): Suggestion Systems: Transferring Employee Creativity Into Practicable Ideas, R\&D Management, 32 (5): 387-395.

Watson, David, David Wiese, Jatin Vaidya, and Auke Tellegen (1999): The Two General Activation Systems of Affect: Structural Findings, Evolutionary Considerations, and Psychobiological Evidence, Journal of Personality \& Social Psychology, 76 (5): 820-838.

Wenger, Etienne (1998): Communities of Practice: Learning, Meaning and Identity, Cambridge University Press: Cambridge et al.

Wood, Robert and Albert Bandura (1989): Social Cognitive Theory of Organizational Management, Academy of Management Review, 14 (3): 361-384.

Zárraga, Celia, and Jaime Bonache (2005): The Impact of Team Atmosphere on Knowledge Outcomes in Self-Managed Teams, Organization Studies, 26 (5): 661-681.

Zerfaß, Ansgar and Kathrin M. Möslein (eds.) (2009): Kommunikation als Erfolgsfaktor im Innovationsmanagement, $1^{\text {st }}$ ed., Gabler: Wiesbaden.

\section{Biographies}

Bastian Bansemir finished his Ph.D. at the Chair for Information Systems I - Innovation \& Value Creation at the University of Erlangen-Nuremberg in 2011 and is currently a post-doctoral research fellow at HHL - Leipzig Graduate School of Management. He graduated from the Technical University of Munich with a Master in business administration (Dipl.-Kfm.). His research focuses on innovation communities. This study was undertaken as part of his dissertation project.

Anne-Katrin Neyer is head of the strategy and organization research group at the Fraunhofer MOEZ (Leipzig). She received her Ph.D. in International Management from the WU Wien and her venia legendi (Habilitation) from the University of Erlangen-Nuremberg. She was a post-doctoral research fellow at the UK's Advanced Institute of Management Research at London Business School. Her major research interests are in the field of inter- and intra-organisational innovation systems and social dynamics of sensemaking in boundaryless organizations.

Kathrin M. Möslein holds the Chair for Information Systems I - Innovation \& Value Creation and serves as research dean at the School of Business and Economics of the University of Erlangen-Nuremberg. She is also a Professor of Management at HHL - Leipzig Graduate School of Management, academic director at HHL's Center for Leading Innovation \& Cooperation (CLIC) and a founding member and, since 2007, Vice President of the European Academy of Management (EURAM). Among others, she serves as member of the advisory boards of the Fraunhofer IIS / SCS, Germany, and the Cambridge Service Alliance (CSA) at the University of Cambridge. Her current research focuses on innovation, cooperation and leadership systems. 